\title{
ERGONOMIC STUDIES ON CONTROLS LAYOUT, DRIVERS ANTHROPOMETRIC AND NOISE EXPOSURE FOR EGYPTIAN FARM TRACTORS
}

\author{
M. A. Eltawil ${ }^{1} \quad$ R. A. Hegazy ${ }^{2}$
}

\begin{abstract}
Tractor driving imposes a lot of physical and mental stress upon the operator. Operator's seat and noise are two of the detrimental factors that lead to unhealthy working conditions for the tractor operator. The optimal design of tractor seat and presence of cabin may be achieved by integrating anthropometric data with other technical features of the design. This paper describes the common Egyptian farm tractor controls layout such as foot brake, foot clutch, foot accelerator (throttle lever), steering wheel, PTO controller, hand brake, hydraulic lever, gear lever and light control buttons. Comparison of noise exposed on the operators of the farm tractors with and without a cabin is investigated. The sound levels $(\mathrm{dB})$ were measured at ear level of the operators. Measurements of anthropometric data were also conducted to match and evaluate the existing main controls layout with driver body dimensions. A two-dimensional measuring device was constructed to measure the tractor controls layout. The measurements were taken as forward horizontal distance and vertical distance from seat reference point (SRP). Observed data indicated that there are large variations in the controls layout on horizontal and vertical axes for different tractor models. Also, large variation was obtained from anthropometric data and responses of drivers. The design of an operator workplace on mobile equipment is frequently a compromise because of conflicting requirements for the limited space available. The use of a cabin was useful in the insulation of the noise, particularly at higher frequencies (under load). The noise levels reached $90 \mathrm{~dB}$ when using tractors without cabins compared to $81 \mathrm{~dB}$ only incase of tractors mounted cabins. The measured noise levels varied also with increasing tractor forward speed as well as load conditions. In addition; cabins protects the operator from the factors having detrimental effects on the working efficiency such as high temperature and dusty environment. Therefore, mounting of cabins on the tractors currently being used without a cab in rental system in Egyptian farms is highly
\end{abstract}

${ }^{1}$ Assoc. Prof., Agric. Eng. Dept., Kafrelsheikh Univ., Egypt

${ }^{2}$ Assistant Prof., Agric. Eng. Dept., Kafrelsheikh Univ., Egypt 
recommended to provide healthy working conditions for their operators.

Keywords: Ergonomic, Tractors, Controls Layout, Anthropometric Noise level,

Cabin

\section{INTRODUCTION}

$\Gamma$ ractor is the most commonly used power source on farms throughout the year, unlike other agricultural machines that have specific and seasonal use. It is used as a prime mover with all kinds of mounted, semi-mounted and trailed equipment. The use of the tractor is not merely confined to farms, but it is also used as the main means of transportation in rural areas. Tractors are also used for stationary applications; taking power from power-take-off (PTO) pulleys for threshing operations and water lifting pumps.

In Egypt, tractors had been introduced during the seventies of the last century and recently number of tractors used in Egypt has reached to 103188 in 2008 (FAO, 2008). Evolution of tractors has accompanied changes in farm technology. Depending upon local and domestic conditions, various types and sizes of tractors have been developed and used worldwide. The tractor has progressed from its original primary use as a substitute for animal power to present units designed for multiple uses. The design of modern tractor includes consideration of human factors because the ultimate objective of ergonomic studies is to optimize the man-machine-environment system to harness greater system efficiency (Day et al., 2005). Generally, new tractors have relatively high safety and ergonomic standards. However, some features, such as operator access to the cab and access for servicing or maintenance, have improved very little over time, and therefore scope remains for improvement in safety features of new model tractors (Walsh et al., 2003). This improvement lead to well-designed human - tractor interfaces, such as well-accommodated tractor operator enclosures (i.e. cabs, hand and foot controls and protection frames) can enhance worker productivity, comfort and safety (Liljedahl et al. 1996).

In Egypt and low-income countries, ergonomic studies on tractors have been very few. In the design process for operator cabs, adjustments for brake reach and linkages, seat position and seat height must be designed to position all potential operators so that they can adequately reach the brake controls and see over the tractor and beyond the protection frames. In addition, some standards related operator controls are intended to 
improve operator efficiency and convenience by providing guidelines for the uniformity of location and direction of motion of operator controls used on agricultural tractors (ASAE, 2004). The controls covered are those located at the operator's normal position. Moreover, the dimensions of the roll-over protective structures (ROPS) should adequately accommodate tractor drivers during normal operation and protect them from injury during a rollover (Hsiao et al., 2003). That's why location of controls should be such that these are easily accessible to the operator. If the operator's controls are not properly adapted to his anatomy, the required performance can not be achieved. Thus possibility of accidents also increased (Patel et al., 2000).

Pheasant and Harris (1982) investigated the pedal position with respect to the seat reference point (SRP) and appropriate driver posture and concluded that ideally pedal location should be $12.5 \%$ stature below SRP and $47.5 \%$ in front of SRP to have a better driving posture and optimum force application. Sjofolt (1982) studied the frequency of looking backwards of a tractor operator. He concluded that while working with farm tractor operator have to spend a large proportion of his time looking backwards and adopting poor working posture. Besides adverse effect to health and general feeling of discomfort, this bad working posture also affects the quality of work. So a rear view mirror was recommended. Kumar et al. (2009) pointed out that, there was a mismatch between the workspace envelope and location of controls as defined by the standard. They mentioned that the controls need a complete change in their layout to be in the workspace envelopes, as this cannot be achieved by providing seat movement in the horizontal and vertical directions in the present tractor design.

The key dimensions to address the tractor controls and work place (i.e. effective anthropometric criteria for tractor design) have not yet been scientifically defined. For agricultural mechanization, no anthropometric data of tractor farm drivers is available for looking into the ergonomic problems of modern mechanization (Viren et al., 2002). For example, if the operator's seat is not comfortable, his work performance may be poor and there is also a possibility of accidents. The optimal design of tractor seat may be achieved by integrating anthropometric data with other technical features of the design. Mehta et al. (2008) reviewed the existing information on the tractor seat design that considers anthropometry and 
biomechanical factors and gives an approach for seat design based on anthropometric data.

Anthropometry, in physical anthropology, refers to the measurement of the human individual for the purposes of understanding human physical variation. Anthropometric dimensions are the initial data used to design the seat and tractor workplace parameters and these data should be only considered in terms of the user population (Haslegrave , 1979). The placement of controls is a complex task for the designer who must take into account the anthropometric characteristics of his target population. The anthropometric dimensions, i.e. popliteal height sitting (5th percentile), hip breadth sitting (95th percentile), buttock popliteal length (5th percentile), interscye breadth (5th and 95th percentile) and sitting acromion height (5th percentile) of agricultural workers need to be taken into consideration for design of seat height, seat pan width, seat pan length, seat backrest width and seat backrest height, respectively, of a tractor.

Today, anthropometry plays an important role in industrial design, clothing design, ergonomics and architecture where statistical data about the distribution of body dimensions in the population are used to optimize products.

Sustained exposure to high noise levels leads to permanent hearing loss. As an example, older tractors and some newer ones (even with cabins) have noise levels above $85 \mathrm{~dB}$ (A) decibels and therefore require hearing protection when the tractor is used (Baker, 2005).

Hearing loss also occurs with the ageing process and it is important to limit the rate of further hearing loss. Hwang et al. (2001) reported that farm noise exposure is a serious risk to the hearing of this population. In their study, 1,622 persons completed the hearing loss and noise exposure interview. Twenty-two percent of participants reported hearing loss. Significant confounders were age, gender, being from a livestock farm, and loss of consciousness due to head trauma. Significant noise exposure was more hours of lifetime exposure to noisy farm equipment or having had a noisy non-farm job.

This paper describes the commonly Egyptian farm tractors controls layout to identify the comfort of operator workplace. Verification of tractor controls layout with driver body dimensions was conducted 
through anthropometric data measurement. A two-dimensional measuring device was constructed to measure the tractor controls layout. The measurements were taken on horizontal and vertical axes from seat reference point (SRP). The noise exposure on tractor operators was investigated in case of loaded and unloaded tractors equipped with and without cabins.

\section{MATERIALS AND METHODS}

In this study, four most popular tractors designated as T1, T2, T3 and T4 were selected. The rated horsepower of tractor models used by Egyptian farmers range from 45 to $120 \mathrm{hp}$. The important specifications of different tractor models used in this study are presented in Table 1.

\section{Table 1. Specifications of different tractors models}

\begin{tabular}{|l|c|c|c|c|}
\hline \multicolumn{1}{|c|}{ Model } & $\begin{array}{c}\text { T1 } \\
\text { (JohnDeere- } \\
\text { 4455) }\end{array}$ & $\begin{array}{c}\text { T2 } \\
\text { (Massey } \\
\text { Ferguson-330) }\end{array}$ & $\begin{array}{c}\text { T3 } \\
\text { (New Holland- } \\
\mathbf{1 1 0 - 9 0}\end{array}$ & $\begin{array}{c}\text { T4 } \\
\text { (Nasr-60) }\end{array}$ \\
\hline PTO, rpm & $540 / 1000$ & $540 / 1000$ & $540 / 1000$ & $540 / 1000$ \\
\hline Diesel cylinders & 6 & 4 & 6 & 4 \\
\hline Cabins & $\begin{array}{c}\text { Sound Guard } \\
\text { cab }\end{array}$ & without & Standard cab & without \\
\hline Horsepower, hp $\mathbf{( k W )}$ & $120(88.32)$ & $45(33.12)$ & $110(80.9)$ & $60(44.13)$ \\
\hline
\end{tabular}

\section{Controls layout}

There are number of controls located in the workspace of tractor. Measurements of tractor workspace parameters are necessary from design and comfort point of view. These parameters included forward horizontal and vertical distances from seat reference point (SRP) for Brake, clutch pedal and throttle lever. In addition to these, steering wheel, PTO controller, hand brake, hydraulic lever, gear lever and light control buttons were also considered in the present study. In case of steering, the wheel diameter, wheel angle, horizontal distance and its vertical distance from SRP were considered (Fig.1). 


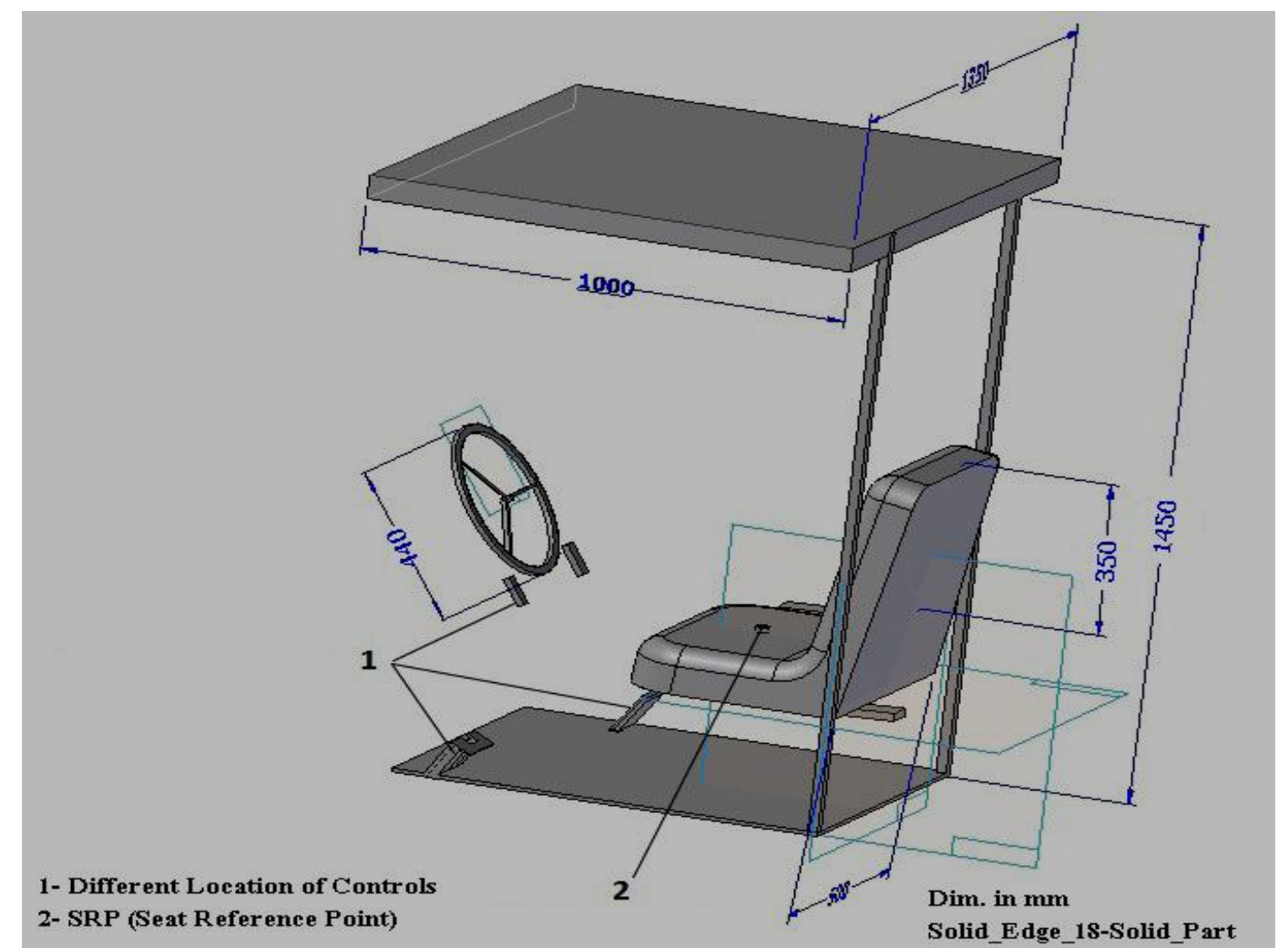

Fig.1. Isometric view of SRP and locations of controls in tractor workspace.

\section{Control layout measuring device}

To measure tractor workspace control parameters, a two-dimensional measuring device was designed. The device consisted of a metal base with $600 \mathrm{~mm}$ diameter. This base carries two vertical scaled columns perpendicular to it. Outer column is fixed to the base and housing another movable column (Inner) with $1000 \mathrm{~mm}$ length. Two horizontal scaled metal rods are attached to the upper of vertical column. Outer one is housing another movable one (inner) with $1000 \mathrm{~mm}$ length to carry measuring tab (Fig.2). The device has the ability to measure distances in vertical and horizontal axes from SRP in addition to lateral distances.

To measure different controls layout, the constructed device was placed inside the tractor workspace at SRP where different measurements were taken (Fig. 3).

\section{Anthropometric data and study survey}

A study survey and anthropometric data were conducted to measure both tractor driver's body dimensions as well as their responses to the existing locations of controls. The first part was related to the anthropometric 
measurements and each driver's body dimensions collected and cited in average for each specific tractor. The second part was a questionnaire distributed and collected from different tractor drivers to measure their response to the existing locations of tractor controls layout.

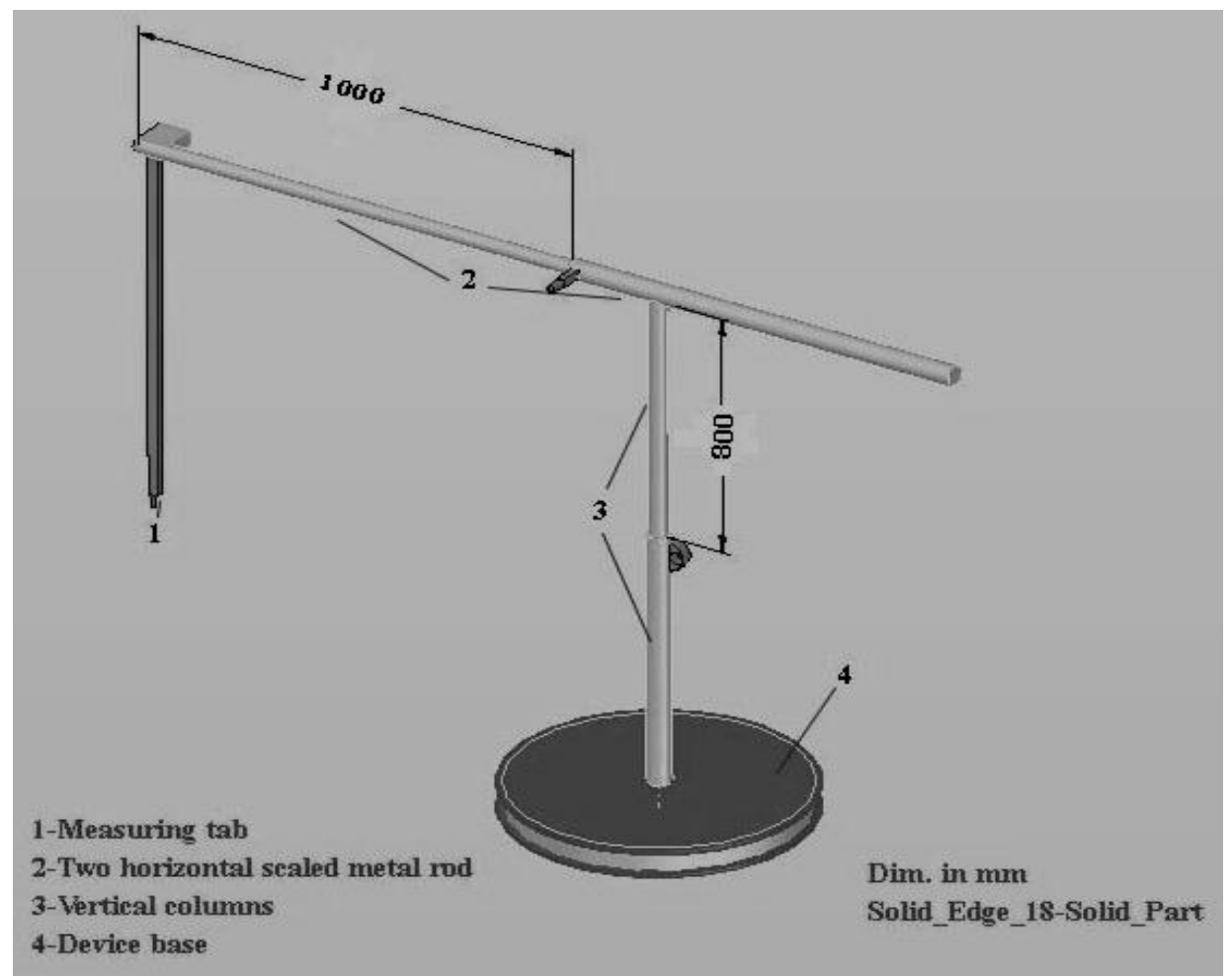

Fig.2. Isometric of the designed device used for control layout measurements

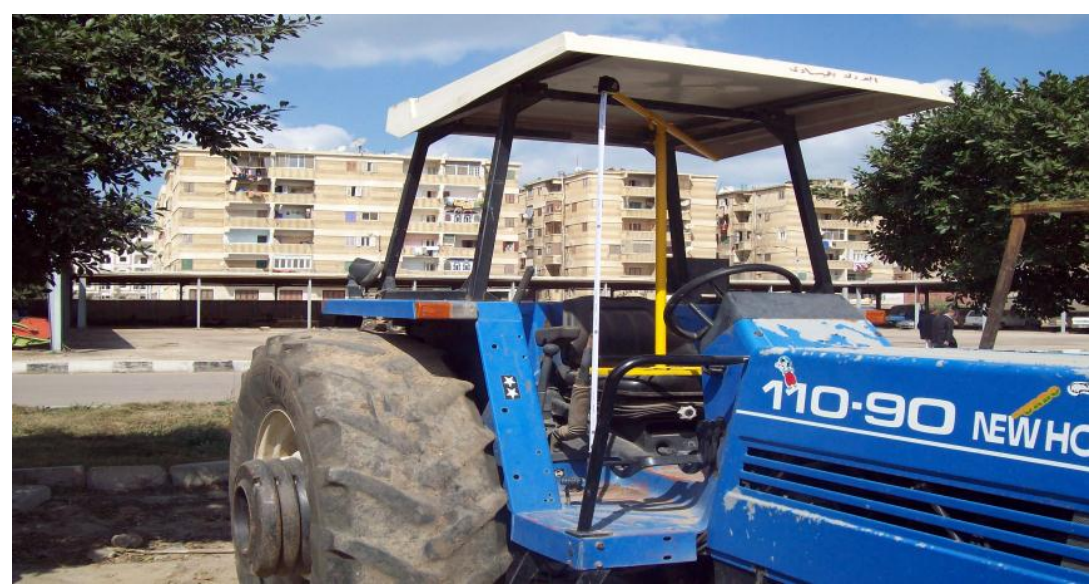

Fig.3. Designed device stands at SRP during measurements (Cabin without sound glass guard). 
The different driver responses were collected and presented as a satisfaction percentage for existing control locations. The survey covered four main tractor models used at Kafrelsheikh region, Egypt in different sites including agricultural research centers, private farms and inside graduate villages. For each tractor model, the questionnaire was distributed between tractor drivers. Thirty questionnaires were selected randomly for each tractor model to analyze the driver's response for existing controls location. Measurements of driver's body dimensions were taken during the survey to collect the anthropometric data. Hence the operator's comfort can be judged.

\section{Noise exposure}

Four different tractor models with and without cabins were tested to verify the effect of noise exposure on tractor operators. The noise level tests were conducted without and with mouldboard plough loads pulled by tractors at different forward speeds ranging from 2.3 to $4.4 \mathrm{~km} / \mathrm{h}$. The operating conditions of the tractors were similar, because crop characteristics (wheat residues) and field surface conditions at the selected sites were nearly the same.

Most noises contain a mixture of sounds with different frequencies. In order to completely determine the composition of a noise, it is necessary to determine the sound pressure level at each frequency individually. Since the human ear is not uniformly sensitive to all frequencies, it is necessary to examine the frequency spectrum of a noise to evaluate the effects of noise on human (Grandjean, 1988).

The noise exposure measurements were taken at the driver ear level with help of sound meter model of SL-5868P, which comply with the requirements of several standards (GB/T 3785, International ElectroTechnical Commission (IEC, 1985)). During experimentations, the sound device was located $20 \mathrm{~cm}$ to the right side of the center plane of the operator's head, in line with the eyes, with its axis parallel to the operator's line of vision (ISO, 1995).

Tests were carried out in the open field using plots of $50 \times 20 \mathrm{~m}^{2}$ since the noise emission of the tractor was steady. All measurements were conducted with 3 replicates and average recorded data were considered. Data analyses were carried out using XL-stat. Analysis of variance was conducted to test significance among variable means as well as standardized residual diagram. 


\section{RESULTS AND DISCUSSIONS}

The results of the study undertaken regarding the controls layout locations in the workspace for different tractors, have been presented and discussed with calculation of total average and standard division (STDEV). Also the data collected from anthropometric measurements, study survey and noise exposure on tractor operator has been discussed.

\section{Location of controls in workspace of different tractors}

\subsection{Brake, clutch pedal and throttle lever}

Horizontal forward distances of brake pedal in all tractor models were in the range of 500 to $600 \mathrm{~mm}$ with an average distance of $537.5 \mathrm{~mm}$ and STDEV of 47.87. For clutch pedal, this distance was observed to be 450 to $550 \mathrm{~mm}$ with an average of $500 \mathrm{~mm}$ and STDEV of 40.82 . The vertical distance of brake and clutch pedal from SRP was in the range of 300 to $400 \mathrm{~mm}$ and 280 to $380 \mathrm{~mm}$ and STDEV was 47.87 and 49.33 , respectively. The forward horizontal distances for throttle lever were in the range of 500 to $750 \mathrm{~mm}$ for selected tractor models while vertical distances varied from SRP and were in the range of 200 to 500 (Fig. 4). The STDEV values for throttle lever were 104.08 and 137 for horizontal and vertical distances from SRP, respectively (Table 2).

\subsection{Hydraulic lever, gear lever and light control buttons}

Results obtained by measuring horizontal and vertical distance for hydraulic lever, gear lever and light control buttons from SRP are shown in Fig. 5. The average forward horizontal distance values for hydraulic lever, gear lever and light control

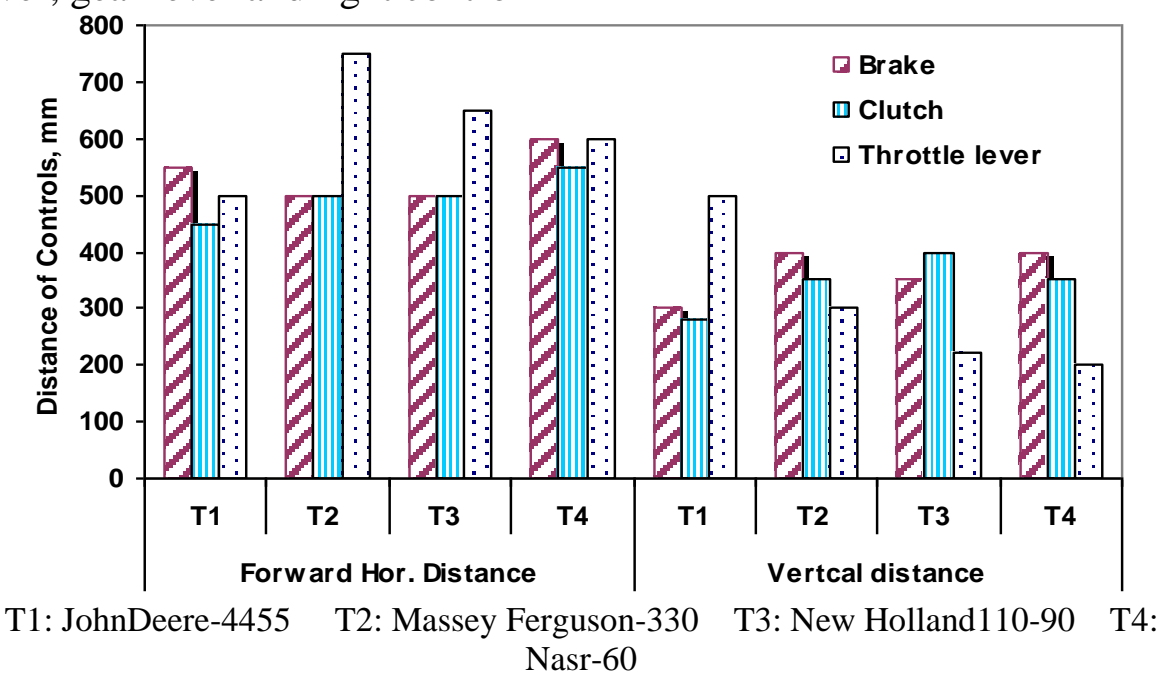

Fig. 4. Comparative location of brake, clutch, throttle lever from SRP in different tractors models. 
Table 2. Total average and standard division (STDEV) for measured distances of controls

\begin{tabular}{|l|c|c|c|c|}
\hline Name of control & $\begin{array}{l}\text { Total average } \\
\text { horizontal } \\
\text { distances, mm }\end{array}$ & $\begin{array}{l}\text { STDEV of } \\
\text { horizontal } \\
\text { distances }\end{array}$ & $\begin{array}{l}\text { Total average } \\
\text { vertical } \\
\text { distances, mm }\end{array}$ & $\begin{array}{l}\text { STDEV of } \\
\text { vertical } \\
\text { distances }\end{array}$ \\
\hline Brake & 537.50 & 47.87 & 362.50 & 47.87 \\
\hline Clutch & 500.00 & 40.82 & 345.00 & 49.33 \\
\hline Throttle lever & 625.00 & 104.08 & 305.00 & 136.99 \\
\hline Hydraulic control lever & 370.00 & 14.14 & 50.00 & 158.11 \\
\hline Gear lever & 442.50 & 43.49 & 100.00 & 122.47 \\
\hline Light control buttons & 570.00 & 54.16 & 175.00 & 64.55 \\
\hline Steering wheel & 362.50 & 62.92 & 325.00 & 52.60 \\
\hline PTO controller & 352.50 & 72.74 & 177.50 & 20.62 \\
\hline Hand brake & 352.50 & 68.50 & 225.00 & 64.55 \\
\hline
\end{tabular}

buttons were $370,442.5$ and $570 \mathrm{~mm}$ with STDEV of 14.40, 43.49 and 54.16 , respectively for all models. The vertical distances measured from SRP to light control buttons were 150, 250, 100 and $200 \mathrm{~mm}$ for T1, T2, $\mathrm{T} 3$ and T4, respectively. The hydraulic and gear levers were placed in the same level with SRP for T2 model and gear lever only for T4. The STDEV was 158.11, 122.47, and 64.55 for hydraulic lever, gear lever and light control buttons, respectively (Table 2).

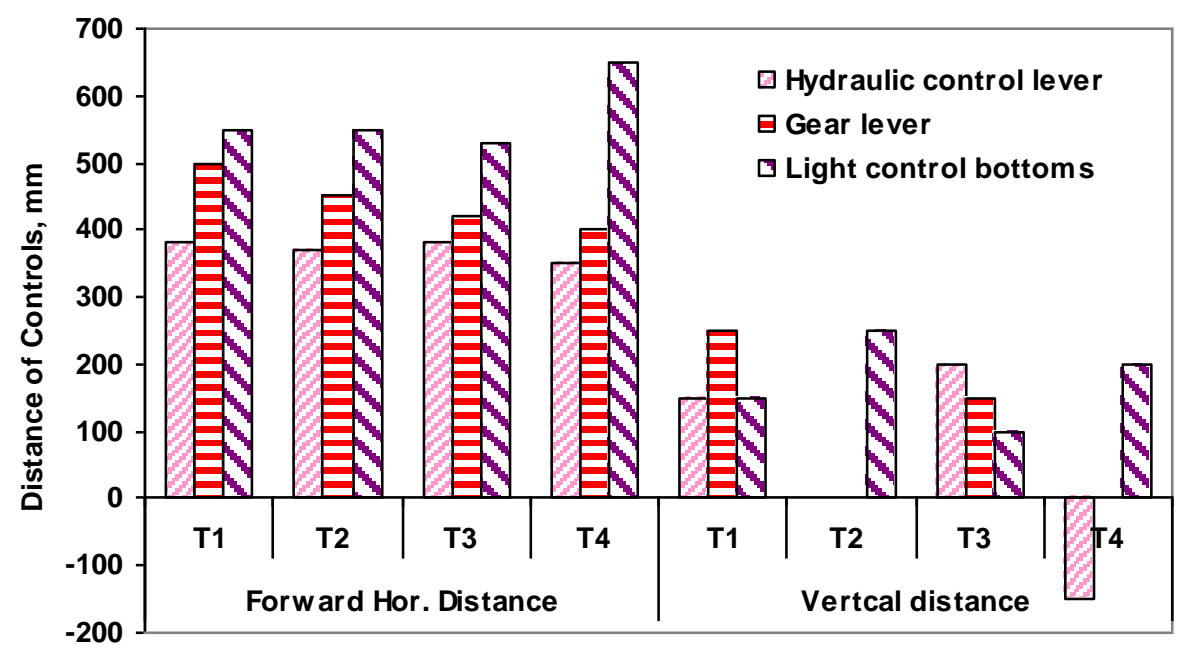

T1: JohnDeere-4455 T2: Massey Ferguson-330 T3: New Holland110-90 T4: Nasr-60

Fig.5. Comparative locations of hydraulic lever, gear lever and light control buttons from SRP in different tractors. 


\subsection{Steering wheel, PTO controller and hand brake}

In all studied tractor models, the horizontal forward distances from SRP were in the range of 300 to 450,280 to 450 and 300 to $450 \mathrm{~mm}$ for steering wheel, PTO controller and hand brake, respectively. The minimum value of vertical distance measured from SRP was $280 \mathrm{~mm}$ for steering wheel in T3, while the lowest vertical distance of $150 \mathrm{~mm}$ was measured for PTO controller in T3. Model T2 had minimum distance of $150 \mathrm{~mm}$ between hand brake and SRP (Fig. 6). The STDEV in horizontal distance from SRP was 62.92, 72.74 and 68 for steering wheel, PTO controller and hand brake. Meanwhile in vertical distances, the STDEV was 52.6, 20.62 and 64.55 for the same controls, respectively.

\section{Anthropometric data and study survey}

Each driver's body dimensions were collected and cited in averages for each specific tractor model. Table 3 depicted the measured drivers' anthropometric data for all studied tractor models. The deferent responses from tractor drivers are also presented in Table 4 and cited as percentages of satisfaction for different existing control locations.

\subsection{Brake, clutch pedal and throttle lever}

Results obtained from survey showed that the tractor drivers gave high existing locations of brake in tractor model $\mathrm{T} 1$ and $\mathrm{T} 3$ followed by $\mathrm{T} 2$ and $\mathrm{T} 4$. The percentages of satisfaction were $95,80,74$ and $65 \%$ for $\mathrm{T} 1$, T3, T2 and T4, respectively with STDEV of 12.61. The parallel anthropmetric data collected from

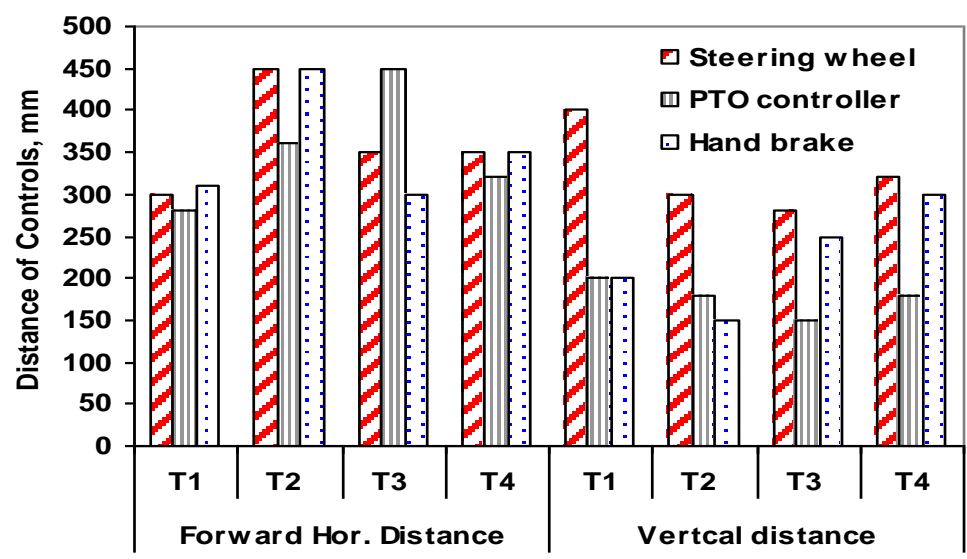

T1: JohnDeere-4455 T2: Massey Ferguson-330 T3: New Holland110-90 T4: Nasr-60

Fig. 6. Comparative locations of steering wheel, PTO controller and hand brake from SRP in different tractors. 
Table 3. Anthropometric data of Egyptian tractor's drivers.

\begin{tabular}{|l|c|c|c|c|c|c|}
\hline Average body dimensions & DT1 & DT2 & DT3 & DT4 & $\begin{array}{c}\text { Total } \\
\text { average }\end{array}$ & STDEV \\
\hline Height, mm & 1700 & 1540 & 1680 & 1720 & 1660.00 & 81.65 \\
\hline Mass, kg & 85 & 78 & 69 & 75 & 76.75 & 6.65 \\
\hline Leg length, mm & 1050 & 930 & 1000 & 1070 & 1012.50 & 62.38 \\
\hline Shoulder width, mm & 420 & 400 & 410 & 420 & 412.50 & 9.57 \\
\hline Thigh length, mm & 440 & 400 & 420 & 430 & 422.50 & 17.08 \\
\hline Foot length, mm & 240 & 220 & 220 & 230 & 227.50 & 9.57 \\
\hline Ankle to sole length, mm & 80 & 80 & 90 & 70 & 80.00 & 8.16 \\
\hline Foot breadth, mm & 80 & 70 & 90 & 90 & 82.50 & 9.57 \\
\hline Arm length, mm & 680 & 610 & 640 & 650 & 645.00 & 28.87 \\
\hline Forearm length, mm & 440 & 380 & 400 & 420 & 410.00 & 25.82 \\
\hline Palm length, mm & 180 & 150 & 160 & 180 & 167.50 & 15.00 \\
\hline Palm breadth, mm & 80 & 70 & 70 & 80 & 75.00 & 5.77 \\
\hline
\end{tabular}

DT1: JohnDeere drivers,

DT2: Massy Fergson drivers,

DT3: New Holland drivers,

DT4: Nasr drivers

Table 4. Survey summery of tractor's drivers comfortability response to existing locations of controls as percentage (\%) of satisfaction.

\begin{tabular}{|l|c|c|c|c|c|c|}
\hline \multirow{2}{*}{ Controls } & \multicolumn{6}{|c|}{ Percentage of satisfaction (\%) } \\
\cline { 2 - 7 } & DT1 & DT2 & DT3 & DT4 & Total average & STDEV \\
\hline Brake & 95 & 74 & 80 & 65 & 78.50 & 12.61 \\
\hline Clutch & 88 & 84 & 67 & 70 & 77.25 & 10.31 \\
\hline Throttle lever & 69 & 48 & 55 & 71 & 60.75 & 11.09 \\
\hline Hydraulic levers & 62 & 66 & 58 & 54 & 60.00 & 5.16 \\
\hline Gear lever & 90 & 74 & 90 & 90 & 86.00 & 8.00 \\
\hline Light Bottoms & 86 & 65 & 75 & 88 & 78.50 & 10.66 \\
\hline Steering wheel & 92 & 79 & 70 & 84 & 81.25 & 9.22 \\
\hline PTO controller & 78 & 75 & 88 & 64 & 76.25 & 9.88 \\
\hline Hand brake & 75 & 64 & 73 & 82 & 73.50 & 7.42 \\
\hline
\end{tabular}

DT1 : JohnDeere drivers,

DT2 : Massy Fergson drivers,

DT3 : New Holland drivers,

DT4 : Nasr drivers

the same tractor drivers showed that average heights of tractor drivers were $1720,1700,1680$ and $1540 \mathrm{~mm}$ for T1, T2, T3 and T4, respectively 
with STDEV of 81.86. The other body parts showed same trend in variation of driver group dimensions under this study.

The drivers of tractor model T1 stated that they can manage freely with the existing brake lever, and this may be because their average height was high compared to tractor drivers of models T2 and T3. Although the average drivers height for model $\mathrm{T} 4$ was also high, only $65 \%$ of drivers expressed their satisfaction about the existing location of brake lever in this model. About 35\% of tractors operators expressed their discomfort with the existing brake location in T4 model. Hence the shortage in design can be demonstrated.

For clutch and throttle lever, the highest satisfaction percentages of their location were 88 and $71 \%$ for T1 and T4 models, while the lowest values were 67 and $48 \%$ for T3 and T4 models, respectively. The satisfaction percentages of clutches location were more than $67 \%$ in all studied tractor models. Meanwhile, it is obvious that the throttle lever location can not guarantee a sufficient satisfaction to wide range of drivers in all tractor models. The satisfaction values were low in all models and reached $48 \%$ in $\mathrm{T} 2$ model.

The operators of $\mathrm{T} 1$ and $\mathrm{T} 4$ models who expressed their highest satisfaction values having an expansion of body parts such as: more height, leg length, foot length and arm length. These body characteristics may enable easy management of the levers of existing controls.

\subsection{Hydraulic lever, gear lever and light control buttons}

More than $50 \%$ of drivers expressed their satisfaction about the locations of hydraulic lever, gear lever and light control buttons in all studied models. The highest satisfaction value about the hydraulic lever was only $66 \%$ for T2 model and was lower for the others models. The lowest satisfaction value of gear lever was $74 \%$ for T2 model and increased to reach $90 \%$ for the other models. The satisfaction percentage of existing light buttons varied from 65 to $88 \%$ for all tractors. The STDEV for hydraulic lever, gear lever and light control buttons was 5.16, 8.00 and 10.66 , respectively.

The parallel anthropometric data collected from same tractor drivers showed that the drivers arm length varied from 610 to $680 \mathrm{~mm}$ with STDEV of 28.87. The drivers groups of models $\mathrm{T} 1$ and $\mathrm{T} 4$ had more expansion in their arm length. The same trend was obtained for drivers forearm length, palm length, palm width and shoulder width. The higher lengths measured for upper body parts of drivers enable them to use hydraulic lever, gear lever and light control buttons in the existing 
locations more efficacy compared to the drivers of other tractor models. That means fixed design concepts for these control locations.

\subsection{Steering wheel, PTO controller and hand brake}

Tractor drivers gave high satisfaction percentage of existing locations of steering wheel in tractor models $\mathrm{T} 1$ and $\mathrm{T} 4$ followed by $\mathrm{T} 2$ and $\mathrm{T} 3$. The percentage of satisfaction was $92,84,79$ and $70 \%$ for T1, T4, T2 and T3, respectively with STDEV of 9.22. The satisfaction percentages were different in case of hand brake, since the drivers expressed their satisfaction with $\mathrm{T} 4$ and lowest value with $\mathrm{T} 2$. The percentage of satisfaction varied from 64 to $88 \%$ for position of PTO controller with STDEV of 9.88. It is obvious that most of the existing locations of controls fit only specific group of drivers especially with more length in arm, forearm and thigh. Except PTO controller whose position gave $88 \%$ of satisfaction with T3 model and this value was the highest between the other model drivers. This means that, the position of PTO is acceptable for most of the drivers even for the specific groups which are smaller in body dimensions.

The safety features in the design of the operator's seat are of prime importance in reducing the static muscle work. The adjustments of seat and controls are required to accommodate operators of different stature and physique comfortably.

According to the survey conducted during this investigation, it was observed that access to the driving seat was awkward for one third of the drivers. The fatigue was experienced by $26 \%$ of the operators interviewed and approximately one fourth of the drivers had medical complaints and back ailments being the most common. Improvements in tractor controls were suggested by $35 \%$ of the operators.

Generally, the horizontal and vertical adjustments of the seat are necessary for variations in leg length and that tractor controls should be placed where they can easily be reached, and operated in such a manner that movement of the control will produce the desired movement of the tractor. The best settings are at which the driver is most comfortable in the cabin and made fewer errors during the driving task. The compromises that must be made to accommodate the working and relaxing modes must come from the results of field research and design experience in each type of vehicle to be used.

\section{Noise exposure on tractor operator}

In general, the loaded tractor gave higher noise values than that unloaded models with or without cabins. Under loaded conditions, the noise level 
in tractors without cabins increased with increasing forward speed except for Tn4 model as shown in Fig 7. The level of noise in the model without load was higher at $3.2 \mathrm{~km} / \mathrm{h}$ forward speed compared to the other forward speeds. The maximum increasing percentage in noise level due to loaded condition was $10.2 \%$ for model Tn1 without cabin at $4.4 \mathrm{~km} / \mathrm{h}$ forward speed. ANOVA analysis showed that there is a high significant effect of cabin mounted on tractors since it reduces the measured noise levels.

Table 5 shows that under loaded condition, the minimum value of noise level was $80 \mathrm{~dB}$ for $\mathrm{Tn} 4$ with cabin at $2.3 \mathrm{~km} / \mathrm{h}$, while maximum noise level was $95 \mathrm{~dB}$ for $\mathrm{Tn} 1$ without cabin at $4.4 \mathrm{~km} / \mathrm{h}$ forward speed. In case of unloaded tractors, the maximum value of noise level was $90 \mathrm{~dB}$ for Tn2 model without cabin at $3.2 \mathrm{~km} / \mathrm{h}$, while the minimum value was 81 $\mathrm{dB}$ for Tn 4 model at $2.3 \mathrm{~km} / \mathrm{h}$ forward speed.

From ANOVA analysis and standardized residual diagram (Fig. 8), it is clear that both load conditions (loaded and unloaded), as well as forward speed, affect the level of noise which can reach and affect driver's ear.

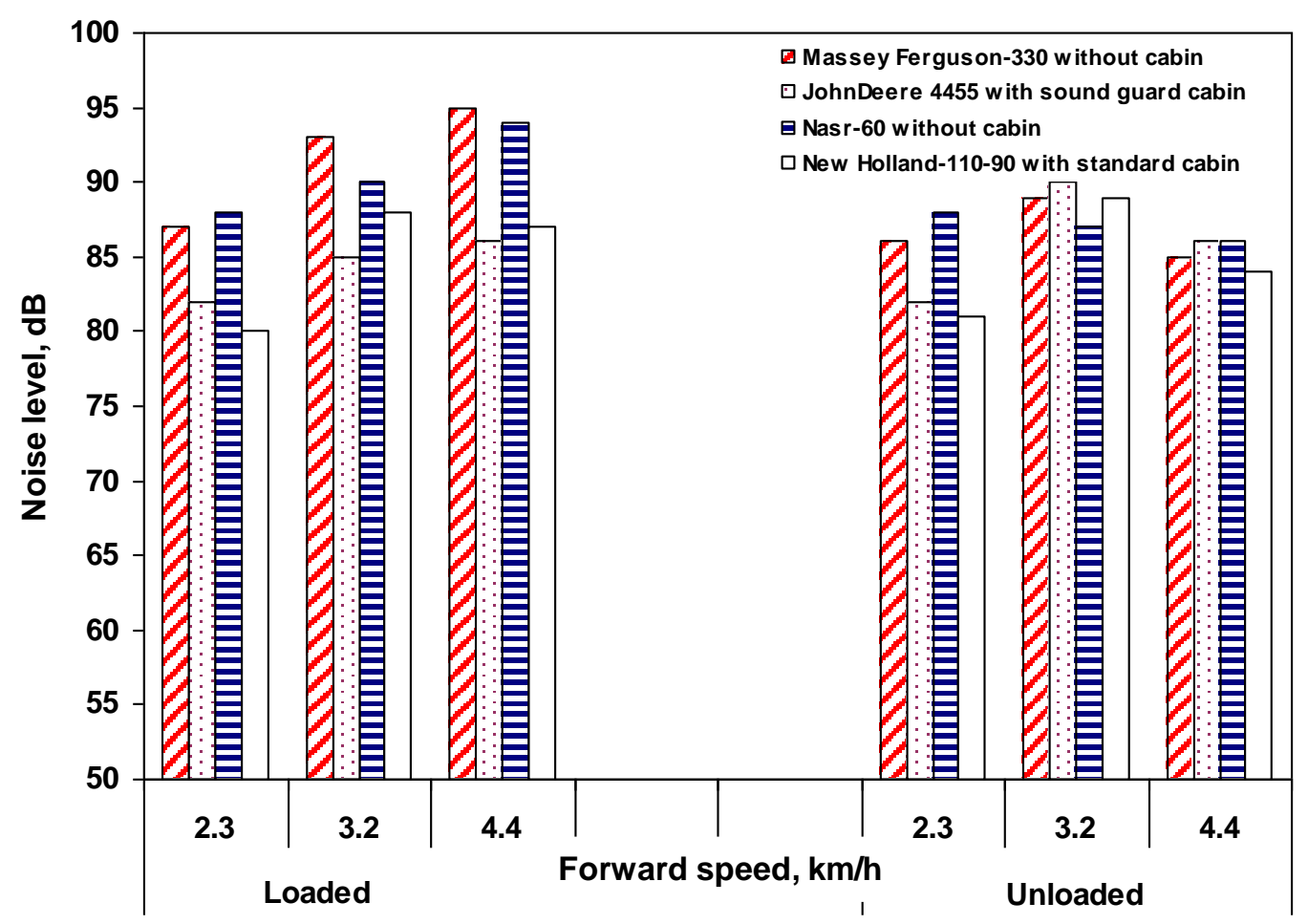

Fig. 7. Noise level in different forward speeds for the different models of tractors with and without cabin on driver's ear. 
Table 5. Comparison of noise level in different forward speeds and load conditions for the different models of tractors with and without cabins at driver's ear.

\begin{tabular}{|l|c|c|c|c|c|c|}
\hline \multirow{2}{*}{ Tractor Model } & \multicolumn{4}{|c|}{ Loaded } & \multicolumn{3}{|c|}{ Not loaded } \\
\cline { 2 - 7 } & \multicolumn{4}{|c|}{ Forward speed, $\mathrm{km} / \mathrm{h}$} \\
\cline { 2 - 7 } & 2.3 & 3.2 & 4.4 & 2.3 & 3.2 & 4.4 \\
\hline Massey Ferguson-330 without cabin (Tn1) & 87 & 93 & 95 & 86 & 89 & 85 \\
\hline JohnDeere4455 with sound guard cabin (Tn2) & 82 & 85 & 86 & 82 & 90 & 86 \\
\hline Nasr-60 without cabin (Tn3) & 88 & 90 & 94 & 88 & 87 & 86 \\
\hline New Holland-110-90 with standard cabin (Tn4) & 80 & 88 & 87 & 81 & 89 & 84 \\
\hline
\end{tabular}

Noise level, $(\mathrm{dB}(\mathrm{A}))$ / Standardized residuals

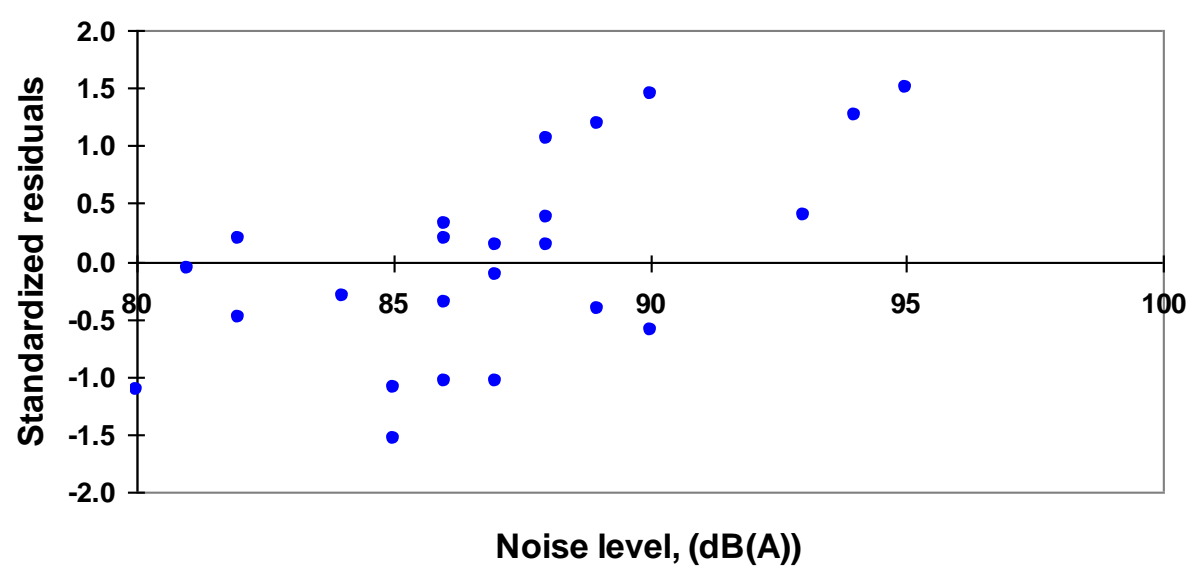

Fig. 8. Standardized residuals show the variation and effects off different variables on noise measured levels.

\section{CONCLUSION}

A successful tractor development makes technical progress profitable for both farmers and tractor manufacturers. Existing Locations of main controls in workspace of tractor vary widely in the different models of Egyptian tractors studied. This variation has advantage on selection of different types according to drivers need, but it has disadvantage for another part of drivers. Most common existing models do not cover the differences of driver body dimensions and need more modification, especially with the category of drivers who have body dimensions below normal. The tractor seat and locations of various hand and foot operated controls should be designed to accommodate $90 \%$ of the driver 
population. Many factors need to be considered for the tractor operator's workplace design. Design criteria for these tractors should be different from place to place especially that the anthropometric data are completely different from region to another and even in the same region. Fatigue was experienced by $26 \%$ of the operators interviewed and approximately one fourth of the drivers had medical complaints. Improvements in tractor controls were suggested by $35 \%$ of the operators. The efficiency and comfort of the operator can be improved with a properly designed tractor workplace. Better designs of seat and controls have resulted in reductions of tractor operator effort and stress. Both the load and speed affect the sound level. Excess sound level due to absence of cabins in tractor is also considered existing defect in studied models which will lead to hearing loss. The exposure hours should be reduced or to wear some kind of ear protection while driving on no cabin tractor, or even with cabin tractor, when using existing models.

\section{REFERENCES}

ASAE (2004). Operator controls on agricultural equipment. Paper no. S335. 4 FEB2004 : 189:192. Niles Rd., St. Joseph, USA (www.asae.org).

Baker, W. (2005). Farm machinery guarding: A practical guide, Australian Centre for Agricultural Health and Safety. P: 8-14.

Day L., M. Scott, R. Williams, G. Rechnitzer, P. Walsh, S. Boyle (2005). Development of the Safe Tractor Assessment Rating System. Journal of Agricultural Safety and Health 11(3): 353-364.

FAO (2008). FAO Statistics Division. Resource STAT-Machinery. Accessed in 06 April 2011.

Grandjean, E. (1988). Fitting the Task to the Man. A Textbook of Occupational Ergonomics. Taylor \& Francis Ltd, London. P: 7880.

Haslegrave C.M. (1979). An anthropometric survey of British drivers. Ergonomics 22(2): 145-153.

Hsiao, H., B. Bradtmiller, and J. Whitestone (2003). Sizing and fit of fallprotection harnesses. Ergonomics, 46: 1233 - 1258.

Hwang S.A., M.I. Gomez, L. Sobotova, A.D. Stark, J.J. May, E.M. Hallman (2001). Predictors of hearing loss in New York farmers. Am J Ind Med 40:23-31. 
IEC (1985). Standard 804: Sound Level Meters. International Electrotechnical Commission (IEC). P:1

ISO (1995). Standard 11202: Acoustic-noise emitted by machinery and equipment-measurement of emission sound pressure levels at a work station and at other specified positions-survey method in situ. International Organization for Standardization (ISO), Switzerland.

Kumar A., G. Bhaskar, J.K. Singh (2009). Assessment of controls layout of Indian tractors. Applied Ergonomics 40: 91-102.

Liljedahl, J.B., P.K. Turnquist, D.W. Amith, and M. Hoki (1996). Tractors and their power units: 226 - 231 (St. Joseph, MI: ASAE).

Mehta, C.R., L.P. Gite, S.C. Pharade, J. Majumder and M.M. Pandey (2008). Review of anthropometric considerations for tractor seat design. Int. J. Indust. Ergonomics 38: 546-554.

Patel, R., A. Kumar, D.Mohan (2000). Development of ergonomic evaluation facility for Indian tractors. Applied Ergonomics v 31, 311-316.

Pheasant, S.T., C.M. Harris (1982). Human strength in the operation of tractor pedals. Ergonomics 25, 53-63.

Sjoflot L. (1982). The tractor as a work place. Ergonomics 25(1): 11-18.

Viren M. V., Saswati Nath, AjayVerma (2002). Anthropometric surveyof Indian farm workers to approach ergonomics in agricultural machinery design. Applied Ergonomics 33:579-581.

Walsh, P. A., L. Day, and M. Scott. (2003). A tractor safety rating system. In Proc. Ag. Equip. Tech. Conf. ASAE, St. Joseph, Mich.

\section{الملخص العربى}

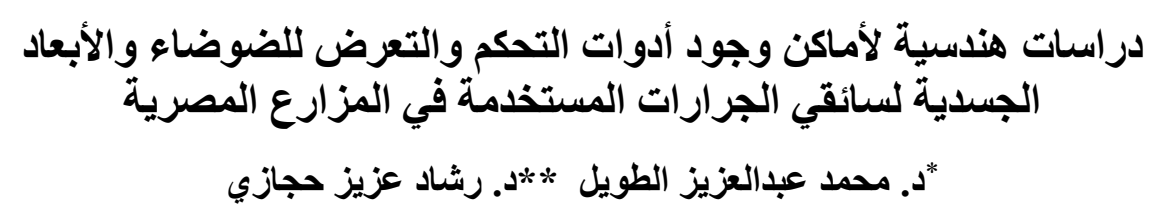

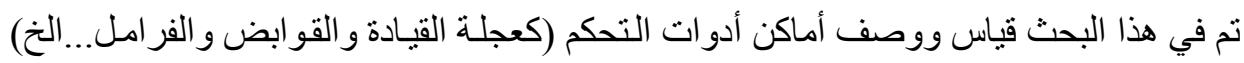

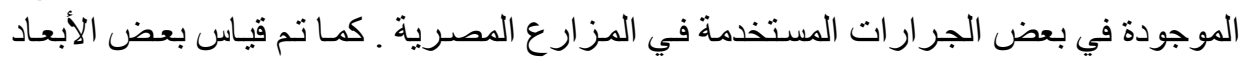

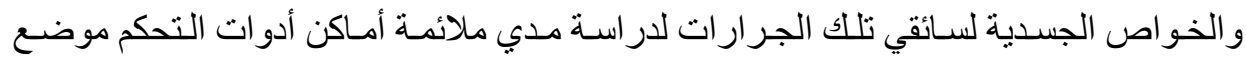

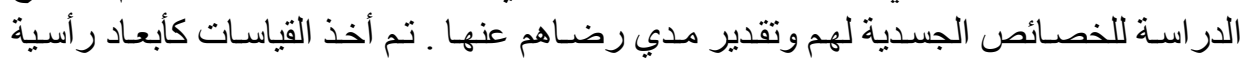

" استاذ مساعد الهندسة الزراعيةـ قسم الهندسة الزراعية _ كلية الزراعةـ جامعة كفرالثيخ.

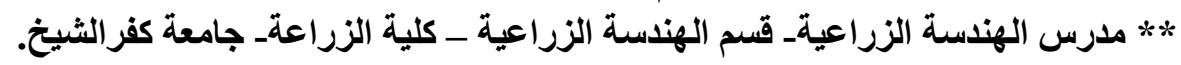


و أفقية وأحيانا جانبية من نقطة معلومة في مركز كرسي الجرار لكل أداة من أدوات التحكم علي

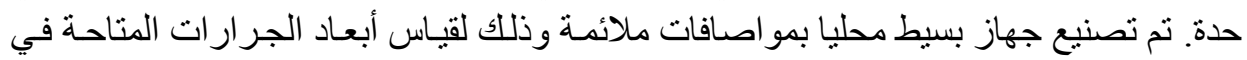

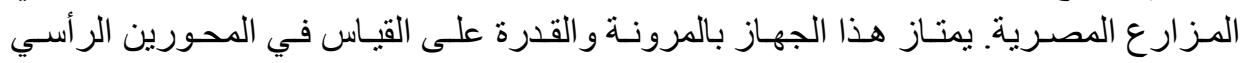

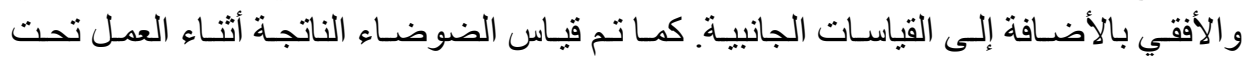

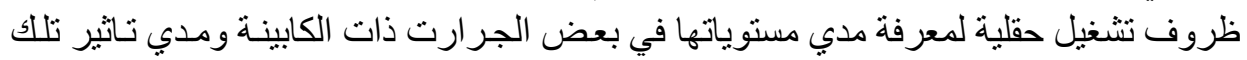

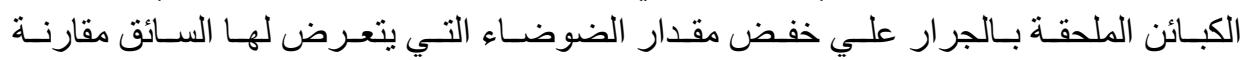

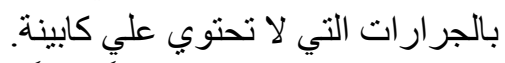

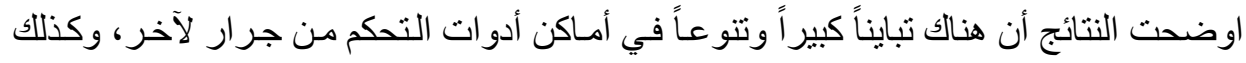

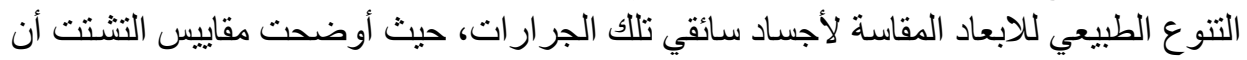

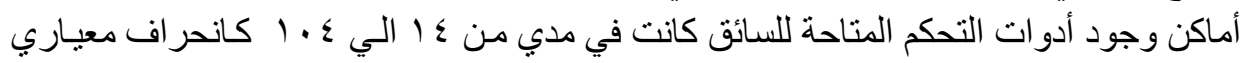

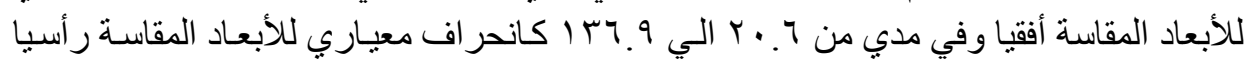
من نقطة القياس الثابتة في الكرسي.

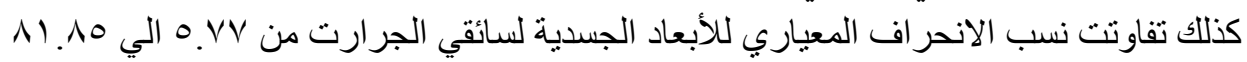

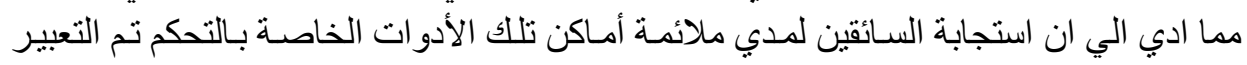

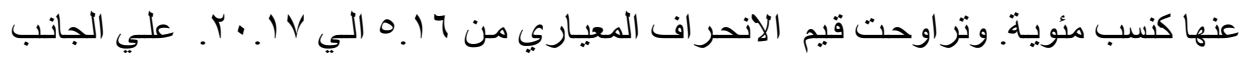

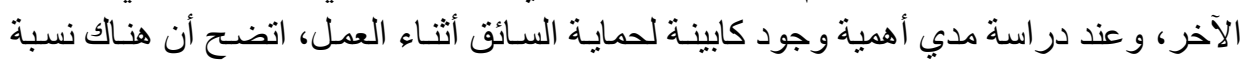

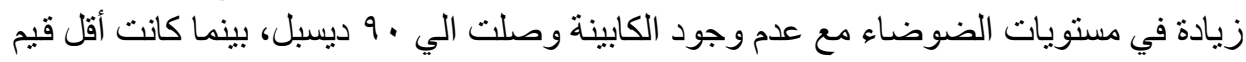

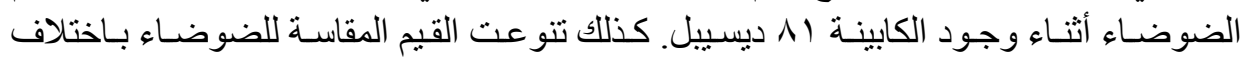

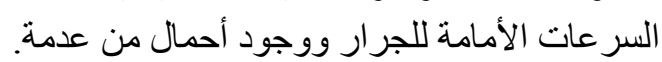

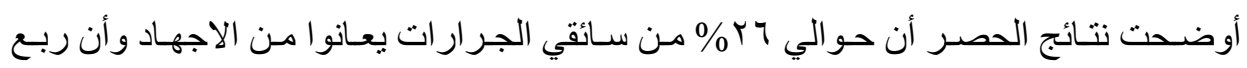

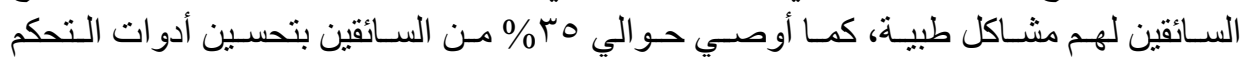
و وأماكنها.

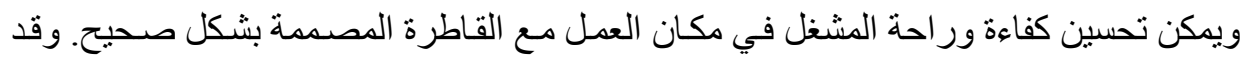

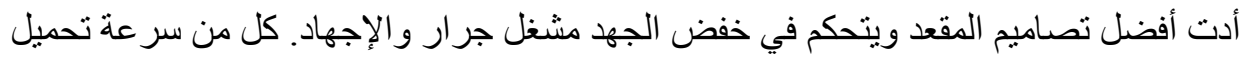

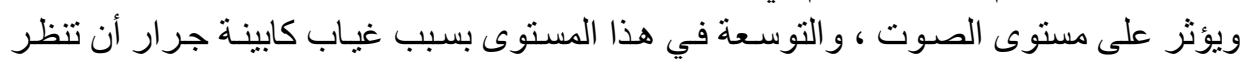

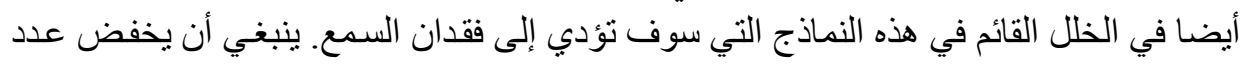

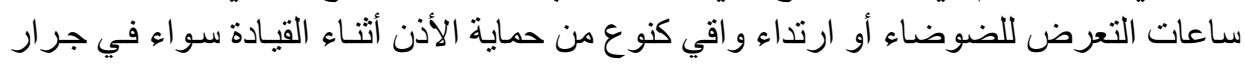
مزود أو غير مزود بكابينة. 